University of Nebraska - Lincoln

DigitalCommons@University of Nebraska - Lincoln

\title{
8-2012
}

\section{Key Findings of the NTM-IMPACT Project}

David Orden

John Beghin

Guy Henry

Follow this and additional works at: https://digitalcommons.unl.edu/ageconfacpub

Part of the Agribusiness Commons, Agricultural Economics Commons, and the Public Affairs, Public Policy and Public Administration Commons

This Article is brought to you for free and open access by the Agricultural Economics Department at DigitalCommons@University of Nebraska - Lincoln. It has been accepted for inclusion in Faculty Publications: Agricultural Economics by an authorized administrator of DigitalCommons@University of Nebraska - Lincoln. 
Published in The World Economy 35:8 (August 2012), pp. 967-972; doi: 10.1111/j.1467-9701.2012.01456.x Copyright (C) 2012 Blackwell Publishing Ltd. Used by permission.

First published August 7, 2012.

\title{
Key Findings of the NTM-IMPACT Project
}

\author{
David Orden, ${ }^{1}$ John Beghin, ${ }^{2}$ and Guy Henry ${ }^{3}$
}

1. Virginia Polytechnic Institute and State University, Arlington, Virginia, USA, and International Food Policy Research Institute, Washington DC, USA

2. Iowa State University, Ames, Iowa, USA

3. Centre de Coopération Internationale en Recherche Agronomique pour le Développement, Montpellier, France, and International Center for Tropical Agriculture, Cali, Colombia

\section{Introduction}

This special issue of The World Economy presents research findings from the European Commission-funded project "Assessment of the impacts of non-tariff measures (NTM)on the competitiveness of the EU and selected trade partners" (NTM-Impact). Directed toward the EU and its trade partners, the project's first overall objective was to collect and analyze new data on NTMs for key and representative agri-food products. This involved three components: creating a large symmetric international database on the diverse types of governmental standards and regulations used to address food safety and quality issues, constructing measures of heterogeneity among these standards and regulations; and evaluating the effects of the heterogeneity of NTMs on agri-food trade. The second overall objective was to undertake detailed case studies of NTMs among the main traders in markets for selected dairy, meat, and fruit and vegetable products. The third objective was to analyze the socioeconomic and trade impacts from private standards on a sample of low- and medium-income developing countries. Collaborators from 19 institutions in five EU and 11 non-EU countries participated in the project.

An aggregate data set of regulations and standards measured on a comparable basis for the EU and nine of its trade partners was collectively assembled by collaborators at 12 institutions. The data assembly effort was coordinated by the NTM-Impact research team at Landbouw Economisch Instituut (LEI). The subsequent aggregate analysis involved collaborators from seven institutions. Seventeen case studies were also completed by project participants. Thirteen of these case studies focused on products and countries that are the 
lead-incumbent, emerging, or high-potential EU export markets. These studies complement the aggregate data collection and its analysis and included developing countries where they are important within a specific trade product cluster. Four case studies focused more intensively on the role of public and private standards on exports to the EU from low- and middle-income developing countries. All of the papers are available on the project website. Drogué and Gervais (2011) provide a summary of the first set of case studies and Bignebat et al. (2011) of the developing country studies.

Well-established theoretical grounds exist for lowering tariffs and other border taxes. They have led to a strong presumption by economists and trade policy leaders that these trade impediments are motivated by protectionism and reduce welfare in most cases. Levels of trade and welfare are both positively correlated with lower tariff rates. A similar presumption is often offered for removing NTMs, although theoretical and empirical grounds for such claims have been weaker. Market imperfections arising from externalities and asymmetric information affect resource allocation, health and the environment. These imperfections call for some regulatory or policy interventions, which may reduce or enhance trade flows. Thus, the linkages among NTMs, trade and welfare are more tenuous than for tariffs. Removing policies that address market imperfections may be suboptimal. Removing these measures may or may not increase trade depending on their net effects on import demand and export supply. Moreover, NTMs often coexist with tariffs and, for agricultural products, tariff-rate quotas (TRQs) and other market interventions, which complicate the design of general policy prescriptions. Very few a priori robust rules emerge, thus NTMs call both for conducting research directed toward aggregated analysis of their prevalence and impacts and for undertaking empirical case studies.

In this context, this special issue presents seven investigations that were selected from the NTM-Impact project research and developed further for publication. ${ }^{1}$ A collective paper under the leadership of Winchester and Rau with eight coauthors describes the datacollection process developed in the NTM-Impact project, construction of the heterogeneity indices and estimation of the impact of regulatory heterogeneity on trade using a gravity model analysis. The collected data and related analysis cover a broad range of import requirements for agricultural and food products. This collective paper is complemented by a reflective query by Humphrey into the evolving regulatory similarities between the EU and the US under the new (2011) US FDA Food Safety Modernization Act.

The remaining five papers delve into the diverse NTM regulations, market structures and other border measures affecting trade of such products as cheese, pigmeat, poultry, fresh lemons, green beans, and mangos. These case studies include EU member states (Denmark, France, Germany, and the Netherlands) and EU trade partners, among them Argentina, Australia, Brazil, Canada, Chile, China, Japan, Mexico, Russia, Senegal, and the United States. A variety of econometric and simulation modeling approaches are utilized, and in the case of Senegal, extensive field data was collected. 


\section{Aggregate Findings}

The NTMs used by the countries covered by the project are technically complex and difficult to evaluate, aggregate, and quantify. Assessment of individual measures requires technical expertise and scientific knowledge in plant science, ecology and animal and human health, among others. The aggregation of disparate measures into indices is also challenging. The weighting scheme used in the aggregation is a priori difficult, as it is hard to know what subset of standards and measures effectively matter from a trade impediment perspective. Hence, the NTM-Impact project's data collection effort dashed any hope to come up with simple aggregation schemes for NTM policy analysis, such as simple count variables.

Winchester and Rau and their coauthors articulate these challenges and describe the procedures followed to develop a comprehensive snapshot of regulatory heterogeneity in 2009-10 between the EU (as a single entity) and nine countries. They estimate the impact of the assessed regulatory heterogeneity on agri-food trade using a gravity model that relied on this extensive data collection. They find that trade is significantly reduced when importing countries have stricter pesticide maximum residue limits for plant products than the exporting countries. For most other measures, often owing to their qualitative nature, they were unable to infer whether the importer has stricter standards relative to the exporter and hence do not find a robust relationship between these measures and trade. The findings suggest that, at least for some import standards, the harmonization of regulations will be trade-increasing. They also conclude from the econometric estimation that tariff reductions remain an effective means to increase trade even when NTMs abound.

The paper by Humphrey adds a dynamic dimension to the complex aggregate assessment of NTM heterogeneity. Humphrey notes that private standards related to food safety have become an important element in trade for fresh fruits and vegetables, particularly for Europe. Discussions of the positive and negative impacts of such standards on farmers in developing countries are associated with the way the standards are implemented and enforced. Enactment of the US FDA Food Safety Modernization Act (FSMA) in January 2011 adds a new element to the discussion of private versus public standards. The Act mandates the introduction of risk-based controls on domestic farms producing fruits and vegetables that are deemed high risk and obligates food importers to ensure that their suppliers utilize equivalent levels of safety controls. Humphrey argues that the FSMA is likely to lead to farm-level controls and certification similar to that seen under European private food safety standards. If so, the heterogeneity of regulations, in terms of some of their practical implications, may diminish over time.

\section{Case Study Findings}

Five case studies address in depth the effects of a diverse set of NTMs across a range of products and trade partners. Some general lessons emerge from these studies. NTMs, whether protectionist and overly restrictive or not, induce significant third-country trade

diversion effects. A story of shifting competitiveness emerges. Exports facing increased 
stringency of NTMs eventually find other markets. A resulting reconfiguration of trade patterns occurs, at times with some significant unintended consequences.

The effects of NTMs on trade and welfare are complex because they are often part of a package of measures rather than a single instrument and because they are often entangled with TRQs, tariffs and other agricultural market interventions with interconnected implications. These cases are beyond robust second-best policy recommendations for a better structure of NTMs. For instance, in the presence of binding TRQs, NTMs may not affect trade volume directly but may create impacts on import unit values and local prices; they clearly affect export revenues and consumer welfare via price effects as shown in the investigation of Canadian dairy compositional standards by Felt, Larue, and Gervais. The complicated alteration of trade patterns following bans owing to the outbreaks of Avian Influenza (AI) are another example of this complexity, as described by Wieck, Schlueter, and Britz. Third countries, which are not directly targeted by the ban, are positively or negatively affected depending on what happens to their poultry exports and prices. Investigations of NTMs based on bilateral data and gravity equations are likely to miss these third-country effects unless the investigations explicitly account for the third-country's policy regimes in their specification. The complementarity of approaches-gravity, multimarket simulation models, time series analysis of unit import values and other techniques-becomes obvious in hindsight given this complexity of effects.

Several of the case studies find evidence of protectionism or former protectionism among their focus countries. In Australia, import quarantines for pork (pigmeat), examined by Beghin and Melatos, were imposed without proper risk assessment, and the initiation of a WTO dispute had to be used to remove some of the offending impediments. Trade bans motivated by AI appear excessive when regionalization within AI-contaminated countries is feasible. Similarly, the risk-based justification for the US ban on Argentine fresh lemons, a case investigated by Cororaton and Peterson, has been challenged. Canadian dairy standards appear to have been imposed for similar protectionist motives, creating divisions within the Canadian dairy industry and motivating criticisms from several of Canada's trade partners.

Despite the complexity and heterogeneity of the effects of NTMs on trade and welfare, the analyses presented here suggest a few policy prescriptions to mitigate their potential protectionist leaning. Blanket bans and quarantines appear gross and suboptimal and rely on poor or inexistent risk assessment in several instances. Regionalization within exporting countries when feasible (such as according to regional disease status in the case of AI) is a more flexible solution relative to bans; it reduces negative welfare and trade effects of the ban while addressing an externality effectively. Allowing trade during certain seasons rather than banning it completely can also be used to address exotic pest risks efficiently. Trading seasonally can induce exporter and domestic consumer gains, as suggested by the US lemon trade investigation. Similarly, proper import risk assessment among pigmeat exporters has created welfare gains for Australia because it allows safe imports to enter the country under controlled conditions while keeping disease risks very low.

Trade negotiations on controversial NTMs are slow and protracted. Importing countries drag their feet with lengthy implementation of risk assessment procedures. This is exemplified by the Australian pigmeat case (where trade has been opened) and the US lemon 
case (where trade with Argentina has not). Resolutions of negotiations concerning NTMs appear at least as protracted as those for tariffs and TRQs. The pigmeat and lemons cases are reminiscent of previous controversial cases among OECD countries on beef hormones, apples and avocados. Several of these negotiations eventually used the WTO dispute settlement mechanism as a last resort negotiation tool.

Several of the findings pertain to North-South trade, addressing the controversies on their role as trade enhancers or trade impediments and the associated interface between NTMs and development. Colen, Maertens, and Swinnen's analysis of mango and green bean production in Senegal and its trade with the EU shows that the adoption by some Senegalese firms of GlobalGAP standards had a positive impact on horticultural labor employment and remuneration compared to firms not adopting these private standards. The effect on employment, both in production and processing, is often overlooked in studies that examine the effects of trade regulation on agricultural smallholders in developing countries.

Finally, the case studies for Australian pigmeat and US lemons explicitly address corner outcomes of zero consumption when imported varieties are originally banned or quarantined but are then introduced or considered for future introduction. The formal treatment of these corners in consumption leads to more rigorous estimates of the prohibitive effect of the NTMs and estimated shadow prices of the banned imports. Welfare gains and trade expansion from the removal of the prohibitive regime are more precisely estimated. Recent applied trade literature has paid much attention to zero trade flows from a supply perspective but few investigations look at the implication of corners in the consumption of imported goods. Hence, the insight gained by the two cases is novel from a methodological perspective.

\section{Notes}

The NTM-Impact Project (European Commission FP7 contract 227202) included researchers from Centre de Coopération Internationale en Recherche Agronomique pour le Développement, France (lead organizing institution); Katholieke Universiteit Leuven, Belgium; Institut National de Recherche Agronomique, France; University of Bonn, Germany; Landbouw Economisch Instituut (LEI), Wageningen, the Netherlands; Institute of Development Studies, University of Sussex, United Kingdom; Instituto Nacional de Tecnologia Agricola, Argentina; University of Sydney, Australia; University of Sao Paulo-ESALQ, Brazil; Université de Laval, Canada; Centre for Chinese Agricultural Policy, China; Research and Information System for Developing Countries, India; Keio University, Japan; Osaka University, Japan; University of Otago, New Zealand; Institute for Agricultural Market Studies, Russia; Slovak University of Agriculture in Nitra, Slovakia; Virginia Polytechnic Institute and State University, USA; and International Food \& Agricultural Trade Policy Council, USA. The project website is www.ntm-impact.eu/.

1. External reviewers included David Abler, Jean Christophe Bureau, Anne-Celia Disdier, Cory Belden, Jacinto Fabiosa, Jason Grant, Tim Josling, Barry Krissoff, Chad Lawley, Stephan Marette, Sebastien Pouliot, Devesh Roy, Norbert Wilson, and Bo Xiong. 


\section{References}

Bignebat, C., L. Colen, J. Humphrey, S. Lemeilleur, M. Maertens, J. Subervie, J. Swinnen, and I. Vagneron (2011), "Private Standards in Fresh Fruit and Vegetable Trade-How to Assist Developing Countries?" Policy Brief Number 11/16, NTM-IMPACT Project.

Drogué, S. and J. P. Gervais (2011), "Policy Implications from the Case Studies," Policy Brief Number 11/18, NTM-IMPACT Project. 